\title{
LEVANTAMENTO FITOSSOCIOLÓGICO DE PLANTAS DANINHAS NA CULTURA DO SORGO GRANÍFERO EM FUNÇÃO DO MANEJO QUÍMICO
}

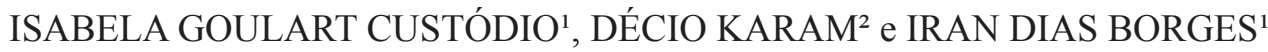

${ }^{1}$ Universidade Federal de São João del-Rei, Sete Lagoas-MG Brasil, isabelacustodio19@yahoo.com.br; idb@ufsj.edu.br ${ }^{2}$ Embrapa Milho e Sorgo, Sete Lagoas - MG Brasil, decio.karam@embrapa.br

Revista Brasileira de Milho e Sorgo, v.18, n.1, p. 148-157, 2019

\begin{abstract}
RESUMO - O objetivo do trabalho foi identificar as plantas daninhas presentes no final do ciclo da cultura do sorgo, após controle químico. O experimento foi conduzido em campo, em delineamento experimental de blocos casualizados, com 23 tratamentos e 3 repetições. Os tratamentos foram aplicações de glyphosate +2 ,4-D $\left(1.500+1.000 \mathrm{~g} \mathrm{ha}^{-1}\right)$ isoladas aos 28, 21 e 7 dias antes da semeadura, e/ou associadas com atrazine + paraquat $\left(1.000+300 \mathrm{~g} \mathrm{ha}^{-1}\right)$ no dia da semeadura, e/ou atrazine (1.000 $\left.\mathrm{g} \mathrm{ha}^{-1}\right)$ isolada ou sequencial em pós-emergência inicial e tardia; um tratamento adicional com atrazine + glyphosate $\left(1.000+1.500 \mathrm{~g} \mathrm{ha}^{-1}\right)$ no dia da semeadura, e duas testemunhas (capinada e sem capina). O estudo fitossociológico foi realizado na pré-colheita do sorgo. As plantas daninhas foram identificadas e quantificadas pelo método do quadrado inventário $\left(0,25 \mathrm{~m}^{2}\right)$, e foram analisados os parâmetros frequência, densidade e abundância, absolutas e relativas, e o índice de valor de importância (IVI). A dessecação aos 28 dias antes da semeadura, associada à aplicação no dia do plantio com herbicidas de contato e residual, somado de aplicações em pós-emergência inicial e tardia, reduziu a frequência, a densidade e a abundância das espécies.
\end{abstract}

Palavras-chave: Sorghum bicolor, BRS 332, fitossociologia, controle.

\section{PHYTOSOCIOLOGICAL SURVEY OF WEEDS IN GRAIN SORGHUM IN THE FUNCTION OF CHEMICAL MANAGEMENT}

\begin{abstract}
The objective of this work was to identify the weeds present at the end of the crop cycle of sorghum after chemical control. The experiment was conducted in a randomized complete block design with 23 treatments and three replicates. The treatments were glyphosate $+2,4-\mathrm{D}(1500+1000 \mathrm{~g}$ ha-1), isolated at 28,21 and 7 days before sowing; and/or atrazine + paraquat $(1000+300 \mathrm{~g}$ ha- 1$)$ on the day of sowing, and/or atrazine $(1000 \mathrm{~g}$ ha- 1$)$ isolated or sequential in early and late post-emergence; an additional treatment with atrazine + glyphosate $(1000+1500 \mathrm{~g}$ ha-1) on the day of sowing, and two controls (weeded and no weed). The phytosociological study was carried out in the pre-harvest of sorghum. Weeds were identified and quantified using the square inventory method $\left(0.25 \mathrm{~m}^{2}\right)$; and the parameters frequency, density and abundance (absolute and relative), and the importance value index (IVI) were Analyzed. The desiccation at 28 days before sowing, associated to the application on the day of planting with contact and residual herbicides, plus initial and late post-emergence applications reduced the frequency, density and abundance of the species.
\end{abstract}

Keywords: Sorghum bicolor, BRS 332, phytosociology, control. 
Sorghum bicolor, de origem africana, é o quinto cereal mais produzido no mundo, e surgiu da intervenção do homem, sendo transformado para satisfazer suas necessidades (Ribas, 2014).

A cultura, vista como uma alternativa à cultura do milho, possui características consideradas vantajosas para os produtores e as indústrias de ração, como o baixo custo de produção e tolerância ao déficit hídrico, sendo capaz de produzir em locais onde outras culturas não se adaptam (Rodrigues, 2015), em função do seu sistema radicular profundo que favorece exploração das camadas do solo (Sodré Filho, 2013).

Apesar de a cultura do sorgo possuir alto potencial produtivo, ela pode sofrer interferência de plantas daninhas pela competição por água, luz e nutrientes (Silva et al., 2014), limitando a produção. A ausência de controle da comunidade infestante durante todo o ciclo do sorgo reduziu $89,6 \%$ no rendimento de grãos (Rodrigues et al., 2010). A diversidade de espécies e a emergência desuniforme dessas plantas dificultam o controle (Karam \& Oliveira, 2015), comprometem a qualidade dos grãos e causam problemas na colheita.

A competição nos estados iniciais de desenvolvimento pode prejudicar a cultura do sorgo se medidas de controle não foram tomadas nas primeiras semanas, levando à redução da produtividade de grãos de $58,5 \%$ e $66,29 \%$, se controladas a partir da oitava e décima semanas após emergência, respectivamente (Passiniet al., 1988). Portanto, conhecer o período crítico de interferência das plantas daninhas é relevante e necessário para efetuar o manejo. De acordo com Andres et al. (2009), em terras baixas de clima temperado, o controle das plantas daninhas deve ser realizado quando o sorgo apresentar três folhas até a emissão de sete folhas.
Os produtores, na maioria das vezes, optam pelo uso de produtos químicos no controle, pelas vantagens no estabelecimento e durante o desenvolvimento da cultura. Entretanto, no Brasil, para a cultura do sorgo há somente duas moléculas registradas: atrazine e 2,4D (Brasil, c2003), desta forma pesquisas de estratégias de manejo se tornam necessárias para um eficiente controle. Dentre estas, as pesquisas no campo da fitossociologia permitem identificar e quantificar as espécies de plantas daninhas em determinado momento do ciclo da cultura, contribuindo, assim, com a tomada de decisões e aplicação de um manejo adequado.

A composição florística da comunidade de plantas daninhas varia em função do tipo e da intensidade dos tratos culturais realizados (Oliveira et al., 2014; Silva et al., 2018). O levantamento fitossociológico, geralmente, é realizado ao final do ciclo das culturas, quando há uma alta infestação de plantas daninhas (Adegas et al., 2010), permitindo analisar os efeitos do manejo sobre essas plantas, conhecendo a comunidade presente.

Com base nisoo, o objetivo deste trabalho foi identificar e quantificar por meio do levantamento fitossociológico as principais plantas daninhas presentes ao final do ciclo da cultura do sorgo, após a realização de estratégias de controle químico.

\section{Material e Métodos}

O experimento foi instalado em campo na área experimental da Embrapa Milho e Sorgo (19² $28^{\prime} \mathrm{S}$ e $\left.44^{\circ} 15^{\prime} 08^{\prime \prime} \mathrm{W}\right)$, localizada no município de Sete Lagoas-MG, clima subtropical úmido de acordo com a classificação de Köppen-Geiger: Cwa.

O delineamento experimental utilizado foi o de blocos casualizados, com 23 tratamentos e 3 repetições (Tabela 1). 
Tabela 1. Tratamentos realizados na cultura do sorgo em campo.

\begin{tabular}{|c|c|c|c|c|c|c|}
\hline \multirow{2}{*}{ Tratamentos } & \multicolumn{4}{|c|}{$\begin{array}{c}\text { Dessecação } \\
\text { (dias antes da semeadura) }\end{array}$} & \multicolumn{2}{|c|}{ Pós-emergência ${ }^{(4)}$} \\
\hline & $28^{(1)}$ & $21^{(1)}$ & $7^{(1)}$ & $\mathbf{0}^{(2)}$ & Inicial & Tardia \\
\hline $28 \mathrm{DAS}$ & $X$ & & & & & \\
\hline $28 \mathrm{DAS}+\mathrm{AP}$ & $\mathrm{X}$ & & & $\mathrm{X}$ & & \\
\hline $28 \mathrm{DAS}+\mathrm{POSi}$ & $X$ & & & & $\mathrm{X}$ & \\
\hline $28 \mathrm{DAS}+\mathrm{POSt}$ & $\mathrm{X}$ & & & & & $\mathrm{X}$ \\
\hline $28 \mathrm{DAS}+\mathrm{POSi}+\mathrm{POSt}$ & $X$ & & & & $X$ & $X$ \\
\hline $28 \mathrm{DAS}+\mathrm{AP}+\mathrm{POSi}$ & $X$ & & & $X$ & $\mathrm{X}$ & \\
\hline $28 \mathrm{DAS}+\mathrm{AP}+\mathrm{POSt}$ & $\mathrm{X}$ & & & $\mathrm{X}$ & & $X$ \\
\hline $28 \mathrm{DAS}+\mathrm{AP}+\mathrm{POSi}+\mathrm{POSt}$ & $X$ & & & $\mathrm{X}$ & $\mathrm{X}$ & $X$ \\
\hline $21 \mathrm{DAS}$ & & $\mathrm{X}$ & & & & \\
\hline $21 \mathrm{DAS}+\mathrm{AP}$ & & $X$ & & $X$ & & \\
\hline $21 \mathrm{DAS}+\mathrm{POSi}$ & & $\mathrm{X}$ & & & $X$ & \\
\hline $21 \mathrm{DAS}+\mathrm{POSt}$ & & $X$ & & & & $X$ \\
\hline $21 \mathrm{DAS}+\mathrm{POSi}+\mathrm{POSt}$ & & $X$ & & & $\mathrm{X}$ & $X$ \\
\hline $21 \mathrm{DAS}+\mathrm{AP}+\mathrm{POSi}$ & & $X$ & & $X$ & $X$ & \\
\hline $21 \mathrm{DAS}+\mathrm{AP}+\mathrm{POSt}$ & & $\mathrm{X}$ & & $X$ & & $X$ \\
\hline $21 \mathrm{DAS}+\mathrm{AP}+\mathrm{POSi}+\mathrm{POSt}$ & & $\mathrm{X}$ & & $\mathrm{X}$ & $X$ & $X$ \\
\hline $7 \mathrm{DAS}+\mathrm{POSi}$ & & & $\mathrm{X}$ & & $X$ & \\
\hline $7 \mathrm{DAS}+$ POSt & & & $X$ & & & $X$ \\
\hline $7 \mathrm{DAS}+\mathrm{POSi}+\mathrm{POSt}$ & & & $X$ & & $\mathrm{X}$ & $X$ \\
\hline $7 \mathrm{DAS}$ & & & $\mathrm{X}$ & & & \\
\hline AP & & & & $X^{(3)}$ & & \\
\hline
\end{tabular}

Capina período todo

Sem capina

(1) Glyphosate + 2,4-D $\left(1188,75+806 \mathrm{~g} \mathrm{ha}^{-1}\right)$

(2) Atrazine + paraquat $\left(1.000+300 \mathrm{~g} \mathrm{ha}^{-1}\right)+0,5 \% \mathrm{v} / \mathrm{v}$ de espalhante adesivo não iônico.

(3) Atrazine + glyphosate $\left(1.000+1188,75 \mathrm{~g} \mathrm{ha}^{-1}\right)$.

(4) Atrazine (1.000 $\left.\mathrm{g} \mathrm{ha}^{-1}\right)$.

DAS - dias antes da semeadura; AP - Aplique-plante; POSi - pós-emergência inicial; POSt - pós-emergência tardia. 
Para as aplicações de atrazine em pós-emergência considerou-se o estádio de desenvolvimento das plantas daninhas; em pós-inicial as plantas de folhas largas com 2 a 3 folhas e as gramíneas antes do perfilhamento, e em pós-tardia, as dicotiledôneas com 4 a 6 folhas e as gramíneas no início do perfilhamento até 2 perfilhos.

A cultivar de sorgo BRS 332 foi semeada em 6 linhas espaçadas de $0,5 \mathrm{~m}$, utilizando-se as linhas centrais como área útil das unidades experimentais de 4 x $7 \mathrm{~m}$. Em pré-colheita do sorgo, 130 dias após emergência, a comunidade infestante foi avaliada pelo método do quadrado inventário (Braun-Blanquet, 1979), lançando-se um quadro de $0,25 \mathrm{~m}^{2}$ duas vezes, aleatoriamente, em cada parcela, sendo as espécies de plantas daninhas identificadas e quantificadas.

Os parâmetros fitossociológicos foram obtidos segundo descrição de Müeller-Dombois e Ellenberg (1974), sendo calculadas as frequências, densidades e abundâncias, absolutas e relativas. O índice de valor de importância (IVI) foi calculado para os tratamentos e para as espécies dentro de cada tratamento com menores IVIs, expresso em porcentagem. Para os cálculos foram utilizadas as seguintes fórmulas:

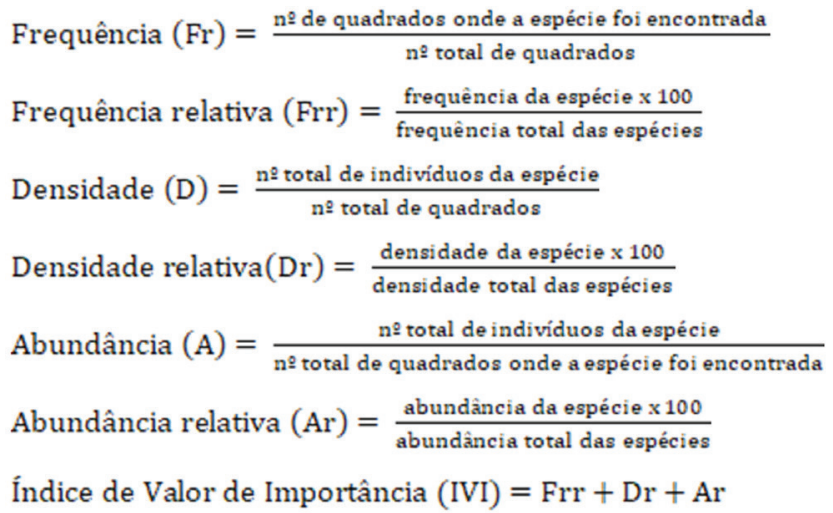

Os dados de Índice de Valor de Importância das plantas daninhas nos tratamentos em que se utilizou o manejo químico foram submetidos ao teste $\mathrm{F}$, e as médias foram comparadas pelo teste de agrupamento de médias de Scott-Knott, a 5\% de probabilidade.

\section{Resultados e Discussão}

No levantamento fitossociológico foram identificadas 18 espécies de plantas daninhas infestando a cultura do sorgo granífero em pré-colheita, distribuídas em 8 famílias (Tabela 2).

As plantas daninhas que pertencem às famílias Poaceae e Asteraceae representam cerca de 50\% das espécies com maior importância mundial (Concenço et al., 2014). Neste levantamento, 39\% das espécies encontradas pertencem à família Poacea, e $22 \%$ à Asteracea. Resultado este que corrobora com Cabral et al. (2013) e Gomes e Karam (2018), que encontraram maior diversidade de espécies gramíneas, na cultura do sorgo granífero.

As espécies que ocorreram em maior densidade, na área experimental, em ordem decrescente, foram Cenchrus echinatus, Urochloa plantaginea, Parthenium hysterophorus e Commelina spp. (Figura 1), o mesmo encontrado por Gomes e Karam (2018), em que a espécie C. echinatus correspondeu a $28 \%$ da população infestante na cultura do sorgo em Sete Lagoas-MG.

Apesar de C. echinatus ter sido encontrado em maior densidade na área, esteve ausente nas parcelas experimentais que apresentavam alta infestação de $U$. plantaginea. Ao passo que, quando o capim-marmelada (U. plantaginea) foi controlado, observou-se grande quantidade do capim-carrapicho (C. echinatus). Este resultado corrobora o de Gimenes et al. (2011), que verificaram redução de $91 \%$ na infestação de $C$. echinatus na presença de $20 \mathrm{Kg} \mathrm{ha}^{-1}$ de B. ruziziensis, e o de Timossi et al. (2007), que observaram elevada massa de $C$. echinatus quando havia menor cobertura 
Tabela 2. Famílias, espécies e nome comum das plantas daninhas identificadas na aérea experimental com sorgo granífero BRS 332.

\begin{tabular}{ccc}
\hline Família & Espécie & Nome comum \\
\hline \multirow{2}{*}{ Amaranthaceae } & Alternanthera tenella & Apaga-fogo \\
\cline { 2 - 3 } & Amaranthus spp. & Caruru \\
\cline { 2 - 3 } Asteraceae & Conyza spp. & Buva \\
\cline { 2 - 3 } & Bidens spp. & Picão-preto \\
\cline { 2 - 3 } & Acanthospermum hispidum & Carrapicho-carneiro \\
\hline Commelinaceae & Corthenium hysterophorus & Losna-branca \\
\hline Convolvulaceae & Ipomoea spp. & Trapoeraba \\
\hline Euphorbiaceae & Euphorbia heterophylla & Corda-de-viola \\
\hline Lamiaceae & Cenchrotiro nepetifolia & Cordão-de-frade \\
\hline & Panicum maximum & Capim-carrapicho \\
\hline & Digitaria spp. & Capim-colonião \\
\hline Poaceae & Digitaria insularis & Capim-colchão \\
\cline { 2 - 3 } & Urochloa plantaginea & Capim-amargoso \\
\cline { 2 - 3 } & Rhynchelitrum repens & Capim-marmelada \\
\cline { 2 - 3 } & Sorghum arundinaceum & Capim-favorito \\
\cline { 2 - 3 } & Richardia brasiliensis & Sorgo selvagem \\
\cline { 2 - 3 } & & Poaia-branca
\end{tabular}

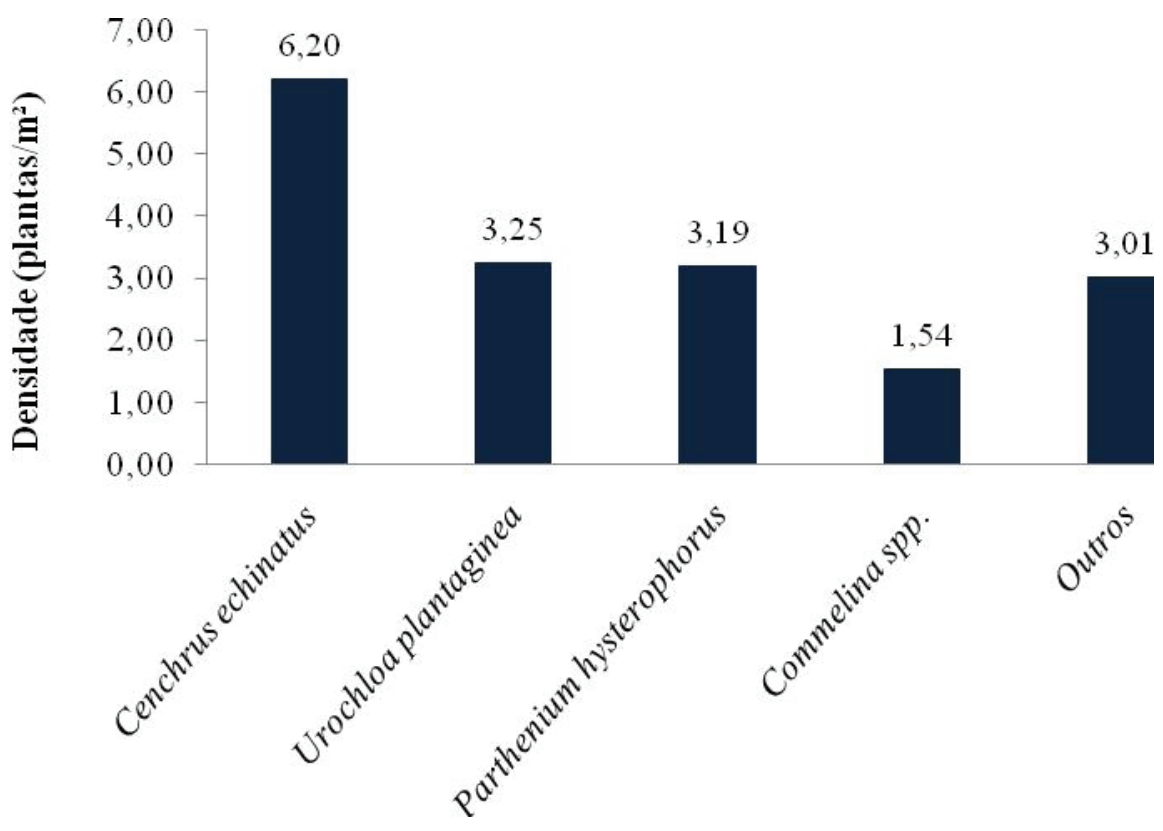

Figura 1. Densidade (plantas $/ \mathrm{m}^{2}$ ) das espécies de plantas daninhas encontrada na área, em pré-colheita, da cultura do sorgo granífero. 
vegetal proporcionada pela B.brizantha. Da mesma forma, o capim braquiária (B.brizantha) apresentou volume de palha suficiente para reduzir a infestação de plantas daninhas em área de milho (Noce et al., 2008).

Gramíneas, como o C. echinatus, ocorrem com frequência em culturas anuais e são muito competitivas por possuírem o mesmo metabolismo C4 que o sorgo (Brighenti \& Oliveira, 2011). O controle químico dessas plantas é dificultado pelo limitado número de herbicidas com ação graminicida registrados para a cultura do sorgo no Brasil (Brasil, c2003).

A probabilidade de encontrar espécies de plantas daninhas, quando se lança aleatoriamente um quadro amostral em uma área, é quantificada através da frequência (Marinho et al., 2017). Analisando este parâmetro, observou-se menor distribuição das espécies, ou seja, menor frequência das plantas daninhas nos tratamentos com dessecação aos 28 DAS + AP, associadas ou não à aplicação em pós-emergência inicial, e adicionada ou não à pós-tardia (sequencial); além dos tratamentos 21 DAS + POSt, $21 \mathrm{DAS}+\mathrm{AP}+\mathrm{POSt}, 21 \mathrm{DAS}+\mathrm{AP}$ + POSi + POSt, e a testemunha capinada (Tabela 3).

O controle químico diminui a incidência das plantas daninhas, reduzindo, consequentemente, os impactos causados à cultura. Portanto, através do Índice de Valor de Importância (IVI) consegue-se identificar a importância das espécies dentro da área amostrada (Marinho et al., 2017). O uso de herbicidas na dessecação aos 28 DAS acompanhado da aplicação no dia do plantio com herbicida de contato e residual (28 DAS + AP), podendo ou não estar associado a aplicações sequenciais em pós-emergência (28 DAS + AP + POSi + POSt), reduziu o IVI, indicando menor importância da comunidade infestante (Tabela1 e Figura 2).

Outros que apresentaram valores de IVI reduzidos iguais a 2,57; 2,01 e 0,81\% foram, respectiva- mente, os tratamentos $21 \mathrm{DAS}+\mathrm{AP}+\mathrm{POSt} ; 21 \mathrm{DAS}$ $+\mathrm{AP}+\mathrm{POSi}+\mathrm{POSt}$ e testemunha capinada (Tabela1 e Figura 2). Contudo, observou-se que a aplicação complementar de atrazine em pós-emergência inicial (21 DAS + AP + POSi) não apresentou semelhança a esses tratamentos em razão da presença de espécies como o C. echinatus e Commelina spp.

O tratamento com dessecação aos 21 DAS + POSt apresentou baixo IVI (Figura 2), fato que pode ser atribuído à baixa infestação de plantas daninhas no momento da aplicação pós-tardia, sendo estas de folhas largas (dicotiledôneas), em que o herbicida foi eficiente, resultando na redução dos parâmetros fitossociológicos. Confirmando a eficiência do herbicida atrazine em diferentes plantas daninhas de folhas largas e algumas folhas estreitas (Brasil, c2003).

O IVI das espécies de plantas daninhas variou com os tratamentos aplicados (Figura 3). Para os tratamentos que se destacaram pelos menores IVIs (Figura 2), as espécies presentes na précolheita do sorgo, foram Alternanthera tenella, Amaranthus spp, Bidens spp., Cenchrus echinatus, Commelina spp., Euphorbia heterophylla, Ipomea spp., Parthenium hysterophorus e Urochloa plantaginea (Figura 3).

A U. plantaginea esteve presente em alta frequência, densidade e abundância na área experimental total, porém, na dessecação aos $28 \mathrm{DAS}+\mathrm{AP}+$ POSi + POSt, onde se verificou o menor IVI, essa planta reduziu a frequência em $66 \%$, a densidade em $95,8 \%$ e a abundância em $87,5 \%$, com relação à testemunha sem capina. Esta espécie quando não controlada causa prejuízos na cultura do milho, reduzindo a produtividade dos grãos em até 98\% (Galon et al., 2010), enfatizando a importância do controle de gramíneas nas culturas. 
Tabela 3. Parâmetros fitossociológicos das plantas daninhas nos tratamentos realizados na cultura do sorgo granífero. D - Densidade; Fr - Frequência; A - Abundância; Dr - Densidade relativa; Frr - Frequência relativa; A - Abundância relativa.

\begin{tabular}{|c|c|c|c|c|c|c|}
\hline \multirow{2}{*}{ Tratamento } & $\mathbf{D}$ & $\mathbf{F r}$ & $\mathbf{A}$ & Dr & Frr & Ar \\
\hline & \multicolumn{3}{|c|}{ Número } & \multicolumn{3}{|c|}{$\%$} \\
\hline $28 \mathrm{DAS}^{(\mathbf{1})}$ & $5^{\mathrm{NS}}$ & $1 a^{*}$ & $5^{\mathrm{NS}}$ & $5,06^{\mathrm{NS}}$ & $5,26 a^{*}$ & $4,47^{\mathrm{NS}}$ \\
\hline $28 \mathrm{DAS}^{(1)}+\mathrm{AP}^{(2)}$ & 1 & $0,67 b$ & 1,5 & 1,01 & $3,51 b$ & 1,34 \\
\hline $28 \mathrm{DAS}^{(\mathbf{1})}+\mathrm{POSi}$ & 4,5 & $1 \mathrm{a}$ & 4,5 & 4,55 & $5,26 \mathrm{a}$ & 4,03 \\
\hline $28 \mathrm{DAS}^{(\mathbf{1})}+$ POSt & 8,5 & $1 \mathrm{a}$ & 8,5 & 8,60 & $5,26 \mathrm{a}$ & 7,60 \\
\hline $28 \mathrm{DAS}^{(\mathbf{1})}+\mathrm{POSi}+$ POSt & 4,17 & $0,83 a$ & 5 & 4,22 & $4,39 \mathrm{a}$ & 4,47 \\
\hline $28 \mathrm{DAS}^{(1)}+\mathrm{AP}^{(2)}+\mathrm{POSi}$ & 2,17 & $0,67 b$ & 3,25 & 2,19 & $3,51 b$ & 2,91 \\
\hline $28 \mathrm{DAS}^{(1)}+\mathrm{AP}^{(2)}+$ POSt & 3,83 & $1 \mathrm{a}$ & 3,83 & 3,88 & $5,26 \mathrm{a}$ & 3,43 \\
\hline $28 \mathrm{DAS}^{(1)}+\mathrm{AP}^{(2)}+\mathrm{POSi}+\mathrm{POSt}$ & 0,67 & $0,33 b$ & 2 & 0,67 & $1,75 b$ & 1,79 \\
\hline $21 \mathrm{DAS}^{(\mathbf{1})}$ & 4,17 & $1 \mathrm{a}$ & 4,17 & 4,22 & $5,26 \mathrm{a}$ & 3,73 \\
\hline $21 \mathrm{DAS}^{(\mathbf{1})}+\mathrm{AP}^{(2)}$ & 3,33 & $0,83 a$ & 4 & 3,37 & $4,39 \mathrm{a}$ & 3,58 \\
\hline $21 \mathrm{DAS}^{(\mathbf{1})}+\mathrm{POSi}$ & 4,17 & $1 \mathrm{a}$ & 4,17 & 4,22 & $5,26 \mathrm{a}$ & 3,73 \\
\hline $21 \mathrm{DAS}^{(\mathbf{1})}+$ POSt & 1,17 & $0,67 b$ & 1,75 & 1,18 & $3,51 b$ & 1,57 \\
\hline $21 \mathrm{DAS}^{(\mathbf{1})}+\mathrm{POSi}+$ POSt & 5,67 & $1 \mathrm{a}$ & 5,67 & 5,73 & $5,26 \mathrm{a}$ & 5,07 \\
\hline $21 \mathrm{DAS}^{(\mathbf{1})}+\mathrm{AP}^{(2)}+\mathrm{POSi}$ & 5,33 & $1 \mathrm{a}$ & 5,33 & 5,40 & $5,26 \mathrm{a}$ & 4,77 \\
\hline $21 \mathrm{DAS}^{(1)}+\mathrm{AP}^{(2)}+$ POSt & 2,17 & $0,5 b$ & 4,33 & 2,19 & $2,63 b$ & 3,88 \\
\hline $21 \mathrm{DAS}^{(1)}+\mathrm{AP}^{(2)}+\mathrm{POSi}+\mathrm{POSt}$ & 2,17 & $0,33 b$ & 6,5 & 2,19 & $1,75 b$ & 5,81 \\
\hline $7 \mathrm{DAS}^{(\mathbf{1})}+\mathrm{POSi}$ & 8,67 & $1 \mathrm{a}$ & 8,67 & 8,77 & $5,26 \mathrm{a}$ & 7,75 \\
\hline $7 \mathrm{DAS}^{(\mathbf{1})}+\mathrm{POSt}$ & 6,33 & $1 \mathrm{a}$ & 6,33 & 6,41 & $5,26 \mathrm{a}$ & 5,66 \\
\hline $7 \mathrm{DAS}^{(\mathbf{1})}+\mathrm{POSi}+\mathrm{POSt}$ & 9 & $1 \mathrm{a}$ & 9 & 9,11 & $5,26 \mathrm{a}$ & 8,05 \\
\hline $7 \mathrm{DAS}^{(\mathbf{1})}$ & 7,33 & $1 \mathrm{a}$ & 7,33 & 7,42 & $5,26 \mathrm{a}$ & 6,56 \\
\hline $\mathrm{AP}^{(3)}$ & 4 & $0,83 \mathrm{a}$ & 4,8 & 4,05 & $4,39 \mathrm{a}$ & 4,29 \\
\hline Capina & 0,33 & $0,33 b$ & 1 & 0,34 & $1,75 b$ & 0,89 \\
\hline Sem capina & 5,17 & $1 \mathrm{a}$ & 5,17 & 5,23 & $5,26 \mathrm{a}$ & 4,62 \\
\hline
\end{tabular}

$\mathrm{DAS}^{(1)}$ - dias antes da semeadura: glyphosate $+2,4-\mathrm{D}\left(1188,75+806 \mathrm{~g} \mathrm{ha}^{-1}\right) . \mathrm{AP}^{(2)}-$ aplique-plante: atrazine + paraquat $(1.000+300$ $\left.\mathrm{g} \mathrm{ha}^{-1}\right)$. $\mathrm{AP}^{(3)}$ - aplique-plante: atrazine + glyphosate $\left(1.000+1188,75 \mathrm{~g} \mathrm{ha}^{-1}\right)$. POSi e POSt - pós-emergência inicial e tardia: atrazine $\left(1.000 \mathrm{~g} \mathrm{ha}^{-1}\right)$.

*Médias na coluna seguidas pela mesma letra não diferiram estatisticamente entre si pelo teste de Scott-Knott a 5\% de probabilidade. NS - não significativo. 


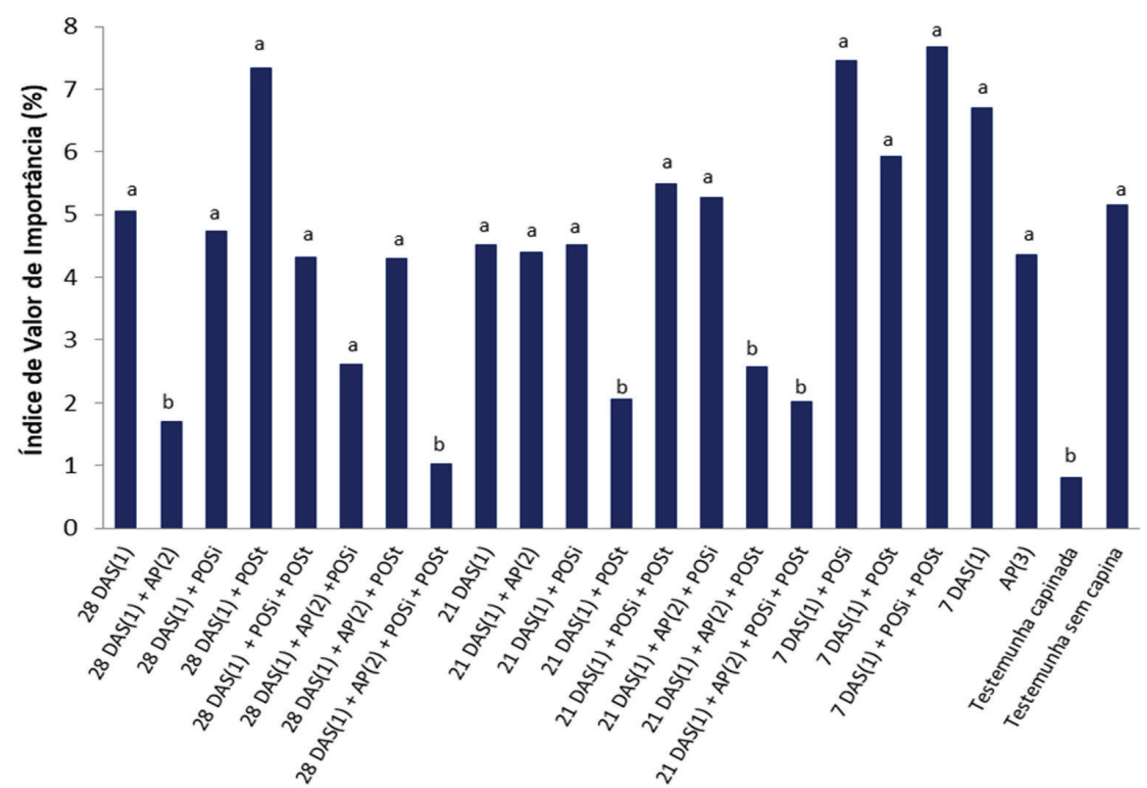

Figura 2. Índice de Valor de Importância das plantas daninhas encontradas após tratamentos aplicados na cultura do sorgo granífero. $\mathrm{DAS}^{(1)}$ - dias antes da semeadura: glyphosate $+2,4-\mathrm{D}\left(1188,75+806 \mathrm{~g} \mathrm{ha}^{-1}\right)$. $\mathrm{AP}^{(2)}$ - aplique-plante: atrazine + paraquat $\left(1.000+300 \mathrm{~g} \mathrm{ha}^{-1}\right)$. $\mathrm{AP}^{(3)}$ - aplique-plante: atrazine + glyphosate $(1.000$ $\left.+1188,75 \mathrm{~g} \mathrm{ha}^{-1}\right)$. POSi e POSt - pós-emergência inicial e tardia: atrazine (1.000 $\left.\mathrm{g} \mathrm{ha}^{-1}\right)$.

Barras seguidas pela mesma letra não diferiram estatisticamente entre si pelo teste de Scott-Knott a 5\% de probabilidade.

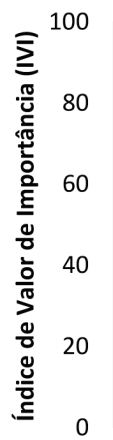

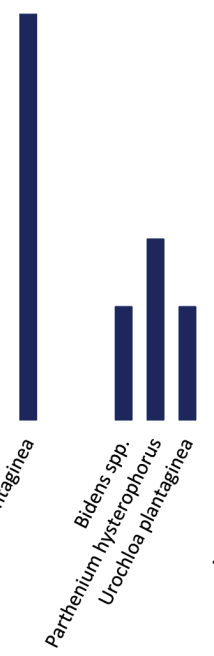

$28 D A S+A P(2) \quad 28 D A S+A P(2)+$

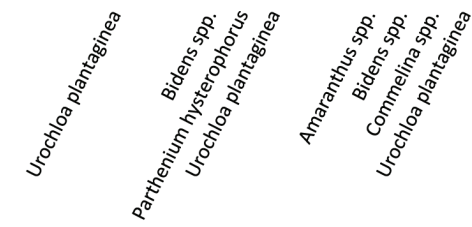

POSi + POSt
21DAS + POSt
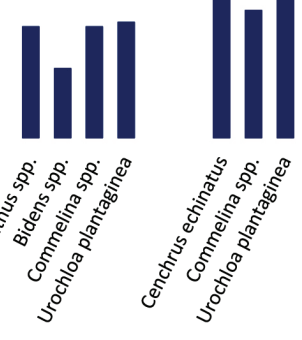

$21 D A S+A P(2)+$
POSt
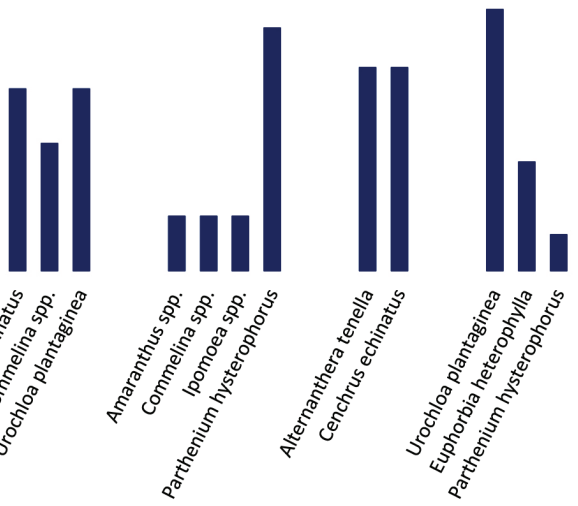

+ AP(2) + POSi Testemunha + POSt capinada capina

Figura 3. Índice de Valor de Importância (IVI) das principais espécies de plantas daninhas identificadas nos tratamentos com menores IVIs, e testemunhas. DAS(1) - dias antes da semeadura: glyphosate + 2,4-D (1188,75 $+806 \mathrm{~g}$ ha-1). AP(2) - aplique-plante: atrazine + paraquat (1.000 + $300 \mathrm{~g}$ ha-1). AP(3) - aplique-plante: atrazine + glyphosate $(1.000+1188,75 \mathrm{~g}$ ha-1). POSi e POSt - pós-emergência inicial e tardia: atrazine (1.000 g ha-1). 


\section{Conclusão}

A alta incidência de Urochloa plantaginea causou supressão do Cenchrus echinatus, dificultando o estabelecimento desta espécie.

A dessecação aos 28 dias antes da semeadura, associada à aplicação no dia do plantio com herbicidas de contato e residual, somada de aplicações em pós-emergência inicial e tardia, reduz a frequência, a densidade e a abundância das espécies.

A ausência das aplicações em pós-emergência (28 DAS + AP) aumenta a importância da U. plantaginea.

As espécies gramíneas, principalmente o capim -marmelada (U. plantaginea), de grande importância neste levantamento, merecem atenção especial, a fim de evitar prejuízos à cultura por serem espécies agressivas e bastante competidoras.

\section{Agradecimentos}

À Coordenação de Aperfeiçoamento de Pessoal de Nível Superior (Capes) pela concessão da bolsa de estudo.

\section{Referências}

ADEGAS, F. S.; OLIVEIRA, M. F.; VIEIRA, O. V.; PRETE, C. E. C.; GAZZIERO, D. L. P.; VOLL, E. Levantamento fitossociológico de plantas daninhas na cultura do girassol. Planta Daninha, Viçosa, MG, v. 28, n. 4, p. 705-716, 2010. DOI: $10.1590 / \mathrm{S} 0100-83582010000400002$.

ANDRES, A.; CONCENÇO, G.; SCHWANKE, A. M. L.; THEISEN, G.; MELO, P. T. B. S. Período de interferência de plantas daninhas na cultura do sorgo forrageiro em terras baixas. Planta Daninha, Viçosa, MG, v. 27, n. 2, p. 229-234, 2009.

DOI: $10.1590 / \mathrm{S} 0100-83582009000200003$.
BRASIL. Ministério da Agricultura, Pecuária e Abastecimento. AGROFIT: sistemas de agrotóxicos fitossanitários. Brasília, DF, c2003. Disponível em: $<\mathrm{http}$ ://agrofit.agricultura.gov.br/agrofit_cons/principal_ agrofit_cons>. Acesso em: 28 nov. 2018.

BRAUN-BLANQUET, J. Fitossociologia: bases para el estudio de las comunidades vegetales. Madri: H. Blume, 1979. $820 \mathrm{p}$.

BRIGHENTI, A. M.; OLIVEIRA, M. F. Biologia de plantas daninhas. In: OLIVEIRA JÚNIOR, R. S. de; CONSTANTIN, J.; INOUE, M. H. (Ed.). Biologia e manejo de plantas daninhas. Curitiba: Omnipax, 2011. p. 1-36.

CABRAL, P. H. R.; JAKELAITIS, A.; CARDOSO, I. S., ARAÚJO, V. T. de; PEDRINI, E. C. F. Interferência de plantas daninhas na cultura do sorgo cultivado em safrinha. Pesquisa Agropecuária Tropical, Goiânia, v. 43, n. 3, p. 308-314, jul./set. 2013

DOI: $10.1590 /$ S1983-40632013000300008.

CONCENÇO, G.; ANDRES, A.; SILVA, A. F.; GALON, L.; FERREIRA, E. A.; ASPIAZÚ, I. Ciência das plantas daninhas: histórico, biologia, ecologia e fisiologia. In: MONQUERO, A. P. Aspectos da biologia e manejo das plantas daninhas. São Carlos, SP: RiMa, 2014. p. 1-10.

GALON, L.; TIRONI, S. P.; FERREIRA, E. A.; ASPIAZU, I.; PINTO, J. J. O. Avaliação do método químico de controle de papuã (Brachiaria plantaginea) sobre a produtividade do milho. Pesquisa Agropecuária Tropical, Goiânia, v. 40, n. 4, p. 414-421, out./dez. 2010.

DOI: $10.1590 /$ S1983-40632010000400019.

GIMENES, M. J.; POGETTO, M. H. F. A. D.; PRADO, E. P.; CHRISTOVAM, R. S.; COSTA, S. Í. A.; SOUZA, E. F. C. Interferência de Brachiaria ruziziensis sobre plantas daninhas em sistema de consórcio com milho. Ciências Agrárias, Londrina, v. 32, n. 3, p. 931-938, jul./set. 2011.

GOMES, T. C.; KARAM, D. Dinâmica populacional de plantas daninhas em áreas com sorgo sacarino e granífero com diferentes espaçamentos e densidades 
de semeadura. Revista Brasileira de Milho e Sorgo, Sete Lagoas, v. 17, n. 3, p. 390-399, 2018. DOI: 10.18512/1980-6477/rbms.v17n3p390-399.

KARAM, D.; OLIVEIRA, M. F. Plantas daninhas. In: RODRIGUES, J. A. S. (Ed.). Cultivo do sorgo. 9. ed. Sete Lagoas: Embrapa Milho e Sorgo, 2015. (Embrapa Milho e Sorgo. Sistemas de Produção, 2).

MARINHO, P. H. A.; SOUSA, R. M. de; MEDEIROS, P. C. A. O.; SILVA, T. G. N.; GIONGO, M. Levantamento fitossociológico de plantas infestantes na área experimental da Universidade Federal do Tocantins submetida a diferentes cultivos. Agrarian Academy, Centro Científico Conhecer, Goiânia, v. 4, n. 7, p. 314324, 2017.

MÜELlER-DOMBOIS, D.; ELlENBERG, H. A. Aims and methods of vegetation ecology. New York: John Wiley, 1974. 574 p.

NOCE, M. A.; SOUZA, I. F.; KARAM, D.; FRANÇA, A. C.; MACIEL, G. M. Influência da palhada de gramíneas forrageiras sobre o desenvolvimento da planta de milho e das plantas daninhas. Revista Brasileira de Milho e Sorgo, Sete Lagoas, v. 7, n. 3, p. 265-278, 2008. DOI: 10.18512/1980-6477/rbms.v7n3p265-278.

OLIVEIRA, A. S.; COELHO, F. C.; CREVELARI, J. A.; FERNANDES, I. S.; RUBIM, R. F. Fitossociologia de plantas daninhas em monocultivo de milho e em consórcio com diferentes Fabaceae. Revista Ceres, Viçosa, MG, v. 61, n. 5, p. 643-651, 2014.

DOI: $10.1590 / 0034-737 X 201461050007$.

PASSINI, T.; ILVA, J. B. da; MORAIS, A. R. de. Efeito da competição de plantas daninhas na cultura do sorgo granífero Sorghum bicolor (L.) Moench. In: CONGRESSO NACIONAL DE MILHO E SORGO, 16., 1986, Belo Horizonte. Anais... Sete Lagoas: Embrapa-CNPMS, 1988. p. 446-453. Disponível em: <http://ainfo.cnptia.embrapa.
br/digital/bitstream/item/47699/1/Efeitos-competicao. pdf $>$. Acesso em: 25 fev. 2019.

RIBAS, P. M. Origem e importância econômica. In: BORÉM, A.; PIMENTEL, L.; PARRELlA, R. (Ed.). Sorgo: do plantio à colheita. Viçosa, MG: Universidade Federal de Viçosa, 2014. p. 188-206.

RODRIGUES, A. C. P.; COSTA, N. V.; CARDOSO, L. A.; CAMPOS, C. F.; MARTINS, D. Períodos de interferência de plantas daninhas na cultura do sorgo. Planta Daninha, Viçosa, $\mathrm{MG}$, v. 28, n. 1, p. 23-31, 2010.

DOI: $10.1590 / \mathrm{S} 0100-83582010000100003$.

RODRIGUES, J. A. S. (Ed.). Cultivo do Sorgo. 9. ed. Sete Lagoas: Embrapa Milho e Sorgo, 2015. (Embrapa Milho e Sorgo. Sistemas de Produção, 2).

SILVA, A. F.; D’ANTONINO, L.; FERREIRA, F. A.; FERREIRA, L. R. Manejo de plantas daninhas. In: BORÉM, A.; PIMENTEL, L.; PARRELLA, R. (Ed.). Sorgo: do plantio à colheita. Viçosa, MG: Universidade Federal de Viçosa, 2014. p. 188-206.

SIlVA, D. A. da; ALBUQUERQUE, J. A. A.; ALVES, J. M. A.; ROCHA, P. R. R.; MEDEIROS, R. D. de; FINOTO, E. L.; MENEZES, P. H. S. de. Caracterização de plantas daninhas em área rotacionada de milho e feijão-caupi em plantio direto. Scientia Agropecuaria, Trijillo, v. 9, n. 1, p. 7-15, 2018. DOI: 10.17268/sci.agropecu.2018.01.01.

TIMOSSI, P. C.; DURIGAN, J. C.; LEITE, G. J. Formação de palhada por braquiárias para adoção do sistema plantio direto. Bragantia, Campinas, v. 66, n. 4, p. 617-622, 2007. DOI: 10.1590/S0006-87052007000400012.

SODRÉ FILHO, J. Consórcio sorgo graníferobraquiária: fitomassa, dinâmica de plantas daninhas e rendimento da soja em sucessão. 2013. 188 f. Tese (Doutorado em Agronomia) - Universidade de Brasília, Brasília, DF, 2013. 